\title{
Intervenção nas situações de crise psíquica: dificuldades e sugestões de uma equipe de atenção pré-hospitalar
}

\author{
Intervention in situations of psychic crisis: challenges and suggestions of a prehospital care staff \\ Intervención en situaciones de crisis psíquica: problemas y sugerencias de un equipo \\ de atención prehospitalaria
}

\begin{abstract}
Alexsandro Barreto Almeida', Eliane Regina Pereira do Nascimento', Jeferson Rodrigues', Gabriela Schweitzer'
' Universidade Federal de Santa Catarina, Centro de Ciências da Saúde, Departamento de Enfermagem, Programa de Pós-Graduação em Enfermagem. Florianópolis-SC, Brasil.
\end{abstract}

\author{
Submissão: 15-10-2012 Aprovação: 15-07-2014
}

\section{RESUMO}

Pesquisa descritiva, qualitativa, que objetivou conhecer como os profissionais de atenção pré-hospitalar percebem as intervenções nas pessoas em crise psíquica. O estudo foi realizado, no estado de Santa Catarina, com quatro equipes das Unidades de Suporte Básico do Serviço de Atendimento Móvel de Urgência, mediante entrevista, no período de abril a junho de 2011. Utilizou-se como método de análise o Discurso do Sujeito Coletivo. Dos resultados emergiram dois temas: Percepção das dificuldades no atendimento à pessoa em crise psíquica e Sugestões na busca por um atendimento mais próximo do desejado à pessoa em crise psíquica. As dificuldades apontadas se relacionam à falta de capacitação e de um local para encaminhamento e sugerem treinamento e sistematização do atendimento. Conclui-se que se faz necessário investir em processo de formação pautado em novas estratégias de cuidado norteadas pelos princípios do SUS e no paradigma psicossocial, além de rediscutir a estratégia de protocolos como sistemas norteadores e não padronizadores.

Descritores: Saúde Mental; Crise; Psiquiatria; Assistência; Urgência.

\begin{abstract}
A qualitative and descriptive research, aimed at knowing how the pre-hospital care professionals perceive the interventions towards people in mental crisis. The study was developed in Santa Catarina with four teams of basic life support units of the Department of Mobile Emergency Care, during April to June 2011. The Collective Subject Discourse was used as the method of analysis. Two themes emerged: Awareness of the difficulties in meeting a person in mental crisis and Suggestions in the search for a closer attention to the person in mental crisis. The difficulties mentioned were related to the lack of training and a local to forward the patients, suggesting a better training and systematization of care. We conclude that it is necessary to invest in the educational process, based on new care strategies guided by the principles of SUS and of the psychosocial paradigm, and revisit the strategy of protocols as guidelines and not as standardizing systems.
\end{abstract}

Key words: Mental Health; Crisis; Psychiatry; Assistance; Urgency.

\section{RESUMEN}

Investigación descriptivo-cualitativa, que objetivó conocer como los profesionales de la atención pre-hospitalaria perciben las intervenciones en personas con crisis mental. El estudió fue realizado en Santa Catarina con cuatro equipos de las Unidades de Soporte Vital Básico, mediante entrevista realizada de abril a junio de 2011. El Discurso del Sujeto Colectivo fue utilizado como método de análisis; surgiendo dos temas: Percepción de las dificultades en la atención a la persona en crisis mental y Sugerencias en la búsqueda de una mejor atención a la persona en crisis mental. Las dificultades mencionadas se relacionan con la falta de capacitación y lugar para la atención, sugiriendo un mejor entrenamiento y sistematización de la atención. Se resalta la necesidad de invertir en el proceso de formación basado en nuevas estrategias de atención guiadas por los principios del SUS y el paradigma psicosocial, y revisar la estrategia de protocolos como nortes no estandarizados.

Palabras clave: Salud Mental; Crisis; Psiquiatría; Asistencia; Urgencia. 


\section{INTRODUÇÃO}

A crise como uma experiência da vida humana é permeada pela necessidade de um cuidado profissional imediato pautado em conhecimento teórico-prático e vinculado a um modelo, para responder à pessoa em crise, coerente com os processos transformadores que impactam a prática interdisciplinar profissional e alinhado às atuais políticas públicas de saúde mental.

Atender à pessoa em crise é encarar a ruptura com a certeza, é dispor-se para um turbilhão que dilacera a vida, uma tempestade de forças que aterrorizam o padrão(1).

A concepção de crise é polissêmica. Isto porque a apropriação conceitual e contextual ofertam diferentes sentidos clínicos, históricos e sociais. No entanto, crise é o desencadeamento psíquico que coloca a pessoa no vazio, em um lugar de interrogação.

Com a implantação da Política Nacional de Saúde Mental, que está pautada na mudança paradigmática de interpretar/responder o fenômeno da loucura, pode-se verificar um investimento na implantação de estruturas de Atenção Pré-hospitalar ao Sujeito em Crise Psíquica, mas ao mesmo tempo, percebe-se uma fragilidade por parte de alguns gestores no processo de capacitação profissional para atender essa demanda. Um dos indicativos dessa dificuldade está relacionado principalmente à escassa literatura referente à atenção à crise ${ }^{(1)}$.

Os sujeitos em grave sofrimento psíquico vivenciam momentos críticos que, por vezes, coincidem com o desencadeamento de um momento de crise, gerando com isso ações confusas e incompreendidas por eles próprios e pelas pessoas que o circundam. Este fato dificilmente se resolve com uma intervenção pontual, pois o momento da crise revela uma tentativa de elaborar um acúmulo existencial e histórico de sofrimento que necessita de uma estratégia ampliada de cuidado. Um dos estratagemas para tentar solucionar o problema do atendimento à urgência dessa clientela é contemplada no Relatório da IV Conferência Nacional de Saúde Mental, com o aumento da cobertura eficaz de transporte móvel para atendimento às emergências em saúde mental com acolhimento adequado, atendimento e remoção qualificados pelo Serviço de Atendimento Móvel de Urgência - SAMU ${ }^{(2)}$.

Com a publicação da Portaria n 2048/GM, instituiu-se a Política Nacional de Atenção às Urgências, na qual foi definido o conceito das urgências psiquiátricas, atestando que estas são de competência técnica dos serviços de urgência. Em 2003, foi aprovada a Portaria $\mathrm{n}^{0} 1864 / \mathrm{GM}^{(3-4)}$, que fundou o componente pré-hospitalar móvel da política de urgência, por intermédio da implantação de Serviços de Atendimento Móvel de Urgência (SAMU). O SAMU tem como dever realizar os atendimentos psiquiátricos, com o propósito de acompanhar os sujeitos em crise até a rede de atendimento de urgência.

Neste sentido, a questão que norteou este estudo foi: como os profissionais da atenção pré- hospitalar percebem as intervenções nas pessoas em crise psíquica? Objetivou-se, pois, conhecer como os profissionais de Unidades de Suporte Básico à vida do Serviço de Atendimento Móvel de Urgência percebem as intervenções nas pessoas em crise psíquica.

\section{REFERENCIAL TEÓRICO}

No ano de 2001, após intensas discussões no Congresso Nacional, é implantada a Política Nacional de Saúde Mental, através da Lei $\mathrm{n}^{\circ} 10.216^{(5)}$. Esta política de Estado dá início a uma mudança no modelo de atenção à saúde mental brasileira que, norteada pelo processo de Reforma Psiquiátrica e os princípios do SUS, passa a ser orientada pelo Paradigma Psicossocial que prioriza os serviços comunitários e territorializados.

A constituição de uma nova forma de cuidado baseada na atenção psicossocial considera necessário refletir e inventar novas concepções e práticas em saúde mental. O paradigma psicossocial pressupõe a aproximação do profissional com o contexto da pessoa, sua história de vida, avaliação clínica e do seu estado mental, para que essa possa manifestar seu sofrimento. Esse contato busca formas de atuação que impliquem na percepção da pessoa em crise como um ser singular, complexo e entrelaçado por uma rede familiar e social.

A configuração do paradigma psicossocial substitutivo ao modelo iatrogênico e cronificador do manicômio, tendo como estratégia de transformação dos saberes e a construção da cidadania dos sujeitos do sofrimento, requer um saber/fazer; diferenciado no contexto da crise psíquica ${ }^{(6)}$. Isto porque ao mesmo tempo em que o sofrimento intenso paralisa a ação profissional, põe em xeque seu saber técnico racional, e é com outro fazer que este mesmo saber se constituirá.

O movimento da Reforma Psiquiátrica constitui um processo permanente de mudanças na forma de pensar a crise, criando estratégias voltadas para a busca da cidadania dos sujeitos em sofrimento psíquico através da garantia de seus direitos. Preconiza-se que a atenção urgente à pessoa em crise reflete um contexto complexo. É essencial visualizar na pessoa que sua crise possui um sentido e, para isso, é esperado um acolhimento dialogado que traga segurança, menos medo e possibilite o estabelecimento de vínculo pela transferência ${ }^{(1)}$.

Essas mudanças profissionais visam transformar as relações com as instituições, com a loucura, com o louco e com o transtorno mental, no sentido de que conduzam uma relação de coexistência, de troca, de solidariedade e de cuidados $^{(7)}$. Para isso se faz necessária a permanente mudança paradigmática do entender a loucura como condição humana, do modelo controlador e asilar para a uma forma libertadora, tendo como possibilidade o Paradigma Psicossocial.

O conjunto das práticas promovidas pelo processo de Reforma Psiquiátrica como Modo Psicossocial é um movimento dialético de contradição ao modelo psiquiátrico tradicional, sendo este último ainda o modelo dominante nas práticas de saúde mental(8). Para configurar a mudança do paradigma de atenção capaz de superar o modelo asilar e/ou paradigma biomédico é imprescindível que a concepção de prática preencha algumas condições relativas a mudanças radicais.

A atenção urgente à pessoa em crise, via de regra, ocorre pelo SAMU ${ }^{(1)}$ e é baseada predominantemente no paradigma biomédico. Esse modelo preconiza o conceito de urgência psiquiátrica associada à agressividade, onde é vista a descompensação patológica (surto) e, em menor tempo possível, se busca a reestabilização mental por meio de contenção química e/ 
ou mecânica. As ações são baseadas em protocolos médicos previamente definidos por diagnósticos e doses de medicação com a finalidade de tornar normal a pessoa em crise.

No paradigma psicossocial a atenção valoriza a subjetividade, o saber e o sentir da pessoa com vista a compreender o que está acontecendo com ela. Busca novas possibilidades para as pessoas em seus momentos de sofrimento. A interação através da clareza que o contexto representa para a equipe entrar em cena tem a finalidade de proporcionar o alívio do sofrimento para a pessoa.

O paradigma psicossocial preconiza que a crise deve ser refletida criticamente ${ }^{(9)}$ e que pode ser revisitada através de algumas categorias $^{(10)}$ como: Concepção do objeto e dos meios de trabalho, seria o olhar dos profissionais frente ao que é a crise e à resposta a essa complexidade e consiste em como as organizações institucionais estão arranjadas para que exista uma Rede de Atenção à Crise potente; Formas do relacionamento com a clientela, significa como ocorrem as relações profissionais, gestoras e familiares com a pessoa em crise e como a troca de saberes entre estes acontecem; Concepção da finalidade em termos terapêuticos e éticos, permite refletir o sentido da crise, o que ela promove de saúde para a pessoa, indica a busca de autonomia e empoderamento. O Modo Psicossocial busca na intervenção da pessoa em crise contribuir com a emancipação, através da ampliação do poder de troca e reprodução que a pessoa tem como potencial(10).

Nesse sentido, o Paradigma de Atenção Psicossocial coloca que além da atenção urgente à pessoa em crise se faz necessária uma ética do cuidado. Essa premissa tem como máxima "não à crueldade" - baseada na empatia, na alteridade e na solidariedade- que valoriza a posição do sujeito, que reconheça a especificidade do saber que vai além da vontade de que a pessoa produza sentido na crise $^{(11)}$. A ética deve ser baseada em princípios vitais da dignidade humana e que promova um cuidado de encontros ${ }^{(1)}$.

\section{METODOLOGIA}

Trata-se de um estudo qualitativo, exploratório-descritivo, realizado no estado de Santa Catarina, com quatro equipes da Unidade de Suporte Básico do SAMU, compostas por um total de 34 profissionais. Estabeleceu-se como critério de inclusão: profissionais da equipe da Unidade de Suporte Básico do SAMU, que prestam atendimento ao público com crise psíquica; a autorização para a gravação das informações e para a publicação dos resultados. Atenderam a esse critério 14 profissionais, sendo que, destes, sete eram técnicos de enfermagem e sete socorristas que atuam como motoristas e na assistência.

A coleta de dados foi realizada no período de abril a junho de 2011, após autorização do Comitê de Ética em Pesquisa da Universidade Federal de Santa Catarina (Parecer N. ${ }^{\circ}$ 1060/11) e assinatura do Termo de Consentimento Livre e Esclarecido dos participantes. Os dados foram coletados por meio de entrevistas semiestruturadas, gravadas e posteriormente transcritas. Aos participantes se perguntou como percebiam a crise psíquica e o atendimento dado pelo SAMU à pessoa em crise. Neste artigo estão contempladas as percepções sobre $\mathrm{o}$ atendimento em crise psíquica. Para garantir o anonimato dos participantes, adotou-se a letra $\mathrm{P}$ (Participante) seguida do número da entrevista.

Para o processo de organização dos dados se utilizou três figuras metodológicas do Discurso do Sujeito Coletivo (DSC): Expressão-chave $(\mathrm{ECH})$, ou seja, trechos que revelam a essência do conteúdo dos depoimentos individuais, fundamentais para a construção do DSC; Ideia Central (IC), expressão que descreve de maneira sintética o sentido de cada conjunto homogêneo de ECHs; e o Discurso do Sujeito Coletivo (DSC), discurso síntese, redigido na primeira pessoa do singular, formado por $\mathrm{ECH}$ s que têm a mesma $\mathrm{IC}^{(12)}$. Para a construção dos DSC, realizou-se a leitura atenta de cada entrevista; o destaque em itálico das expressões chaves (ECHs) de cada discurso individual; o agrupamento das $\mathrm{ECH}$ s de mesmo sentido nos diferentes discursos individuais; a identificação da Ideia Central (IC) do conjunto das $\mathrm{ECH}$ de mesmo sentido, de sentido equivalente, ou de sentido complementar e que compuseram o DSC. Os DSC estão representados por DSC1 e DSC2. Optou-se, por não apresentar no artigo as ECHs e, sim, os discursos que as compõem, para evitar repetição na apresentação dos dados, uma vez que nos DSC estão contempladas as $\mathrm{ECH}$ s dos discursos individuais, com a mesma IC. Os resultados foram discutidos à luz do paradigma psicossocial.

\section{RESULTADOS}

Dos resultados encontrados emergiram dois DSC com os temas: Percepção das dificuldades no atendimento à pessoa em crise de saúde mental, constituído com ECHs de 11 participantes, apresentado no Quadro 1; e, Sugestões na busca por um atendimento mais próximo do desejado à pessoa em crise psíquica, referente a ECHs de 10 profissionais, conforme o Quadro 2.

Quadro 1 - Percepção das dificuldades no atendimento à pessoa em crise de saúde mental

\begin{tabular}{|c|c|}
\hline IC & DSC 1 \\
\hline $\begin{array}{l}\text { Falta preparo } \\
\text { para o } \\
\text { atendimento }\end{array}$ & $\begin{array}{l}\text { Acredito que a experiência do dia a dia me faz ter } \\
\text { certo preparo técnico, mas com dificuldade na } \\
\text { questão psicológica. Por ser o SAMU um serviço } \\
\text { de Urgência e Emergência, e não de continuação } \\
\text { do cuidado realiza-se o necessário, mas acho que } \\
\text { poderíamos ter um preparo melhor. Fico muito em } \\
\text { alerta a tudo o que o paciente faz, a forma dele } \\
\text { agir e de se expressar. Eu abordo porque tem que } \\
\text { abordar mas eu não me sinto preparado. Pode-se } \\
\text { dizer que estou preparado na medida do possível, } \\
\text { pois consigo realizar técnicas para contenção fí- } \\
\text { sica, mas não psicológica. Em algumas situações } \\
\text { não me sinto preparado e abordo a pessoa com a } \\
\text { presença da polícia militar. No caso de agressivi- } \\
\text { dade não me sinto preparado. Acredito que preci- } \\
\text { saríamos de mais orientação, pois é a única área } \\
\text { que a gente não tem capacitação. Quando consigo } \\
\text { me aproximar, na abordagem, a pessoa fica tran- } \\
\text { qüila, mas quando não, é na força mesmo. Com } \\
\text { certeza precisa mais coisa para o atendimento, } \\
\text { orientação. Acredito que a falta de preparo e de } \\
\text { conhecimento associada ao estigma do medo, faz } \\
\text { com que o atendimento siga uma forma não corre- } \\
\text { ta (P1,P2,P3.P4,P5,P6,P7,P9,P10,P13,P14). }\end{array}$ \\
\hline
\end{tabular}


Além das dificuldades apresentadas pelas equipes, os dados analisados retratam sugestões que a equipe aponta para melhor atender a pessoa em crise psíquica.

Quadro 2 - Sugestões na busca por um atendimento mais próximo do desejado à pessoa em crise psíquica.

\begin{tabular}{|l|l|}
\hline \multicolumn{1}{|c|}{ IC } & \multicolumn{1}{c|}{ DSC 2} \\
\hline $\begin{array}{l}\text { Capacitação e } \\
\text { sistematização } \\
\text { do atendimento }\end{array}$ & $\begin{array}{l}\text { Acredito que seria necessário um treinamento } \\
\text { para a equipe, onde aprenderíamos como agir } \\
\text { nas situações. Outro ponto importante seria } \\
\text { o aumento de psiquiatras na rede de atendi- } \\
\text { mento de emergência, ter hospitais ou clínicas } \\
\text { que aceitassem esses pacientes pelo SUS. Só } \\
\text { tem uma que aceita, o IPQ. Outra coisa seria } \\
\text { principalmente a criação de uma sistematiza- } \\
\text { ção do atendimento para o SAMU. Precisa ter } \\
\text { capacitação, educação continuada, inclusive } \\
\text { para saber como abordar e como segurar a pes- } \\
\text { soa. Temos que saber como segurar a pessoa } \\
\text { em crise. A gente tenta não fazer força, mas } \\
\text { é preciso. Tem que ter mais cursos, palestras } \\
\text { para as equipes de APH, SAMU, bombeiro e } \\
\text { até para a polícia. Ter mais acompanhamento } \\
\text { para a família. A psiquiatria é uma coisa com- } \\
\text { plicada, porque o paciente quando está em } \\
\text { surto, o médico do SAMU manda dar a medi- } \\
\text { cação para proteção da equipe e acabo com- } \\
\text { plicando o lado do paciente porque quando } \\
\text { chego ao hospital com o paciente o médico } \\
\text { me questiona como eu trago um paciente dor- } \\
\text { mindo. Deveríamos ter uma equipe especiali- } \\
\text { zada no SAMU ou então não atender esse pú- } \\
\text { blico, pois não é demanda para o SAMU (P1, } \\
\text { P2, P3, ... P10) }\end{array}$ \\
\hline
\end{tabular}

\section{DISCUSSÃO}

Pode-se perceber no DSC1 uma dificuldade no atendimento devido a um déficit de conhecimento técnico para as ações em situações de crise psíquica no campo da saúde mental, pois essas ações estão embasadas em conhecimento empírico e pessoal sustentado no modelo biomédico. Constata-se, pelo paradigma psicossocial, uma necessidade de mudança no atendimento discursado, tanto na perspectiva do trabalhador quanto na perspectiva da organização dos serviços, pois as dificuldades apontadas revelam despreparo profissional e sentimentos de estranhamento que a crise representa.

Em relação ao (des)preparo profissional para atender à pessoa em crise psíquica, vale apontar que a concepção de atendimento pré-hospitalar (APH) se caracteriza por toda e qualquer assistência realizada fora do âmbito hospitalar em situações de urgência e emergência, contendo ou não risco de morte $^{(13)}$. Entendendo-se esse processo de formulação de serviço baseado em patologia clínica e de ação imediata se contrapõe a um entendimento de saúde ampliado, em que o grau de sofrimento é individualizado e por consequência há a necessidade de intervenções complexas e singulares. Essa compreensão ampliada depende de concepções teóricas que se adotem para guiar a ação educativa, seja nos cursos de formação técnico acadêmico, seja na educação permanente e em serviços.

As diretrizes que envolvem o preparo para a Atenção Pré-hospitalar à pessoa em crise encontram, no Serviço de Atenção Móvel de Urgência (SAMU), um dos principais instrumentos para sua efetivação. Esse serviço tem por finalidade prestar socorro à população em casos de urgência, buscando reduzir o número de óbitos, o tempo de internações em hospitais e as sequelas decorrentes da falta de socorro precoce ${ }^{(14)}$.

É no campo das situações de Urgência que a Crise se insere. A resolução do Conselho Federal de Medicina define como Urgência a ocorrência imprevista de agravo à saúde, com ou sem risco potencial de vida, cuja pessoa necessita de assistência médica imediata ${ }^{(15)}$.

A urgência e crise no campo da saúde mental requerem definições e discussões entre gestores e trabalhadores do SAMU para promover principalmente consensos na intervenção. Porém, sabe-se que a crise depende de como o profissional interpreta o fenômeno, de como ele constrói seu arsenal de concepções e práticas, a partir desse entendimento ${ }^{(16)}$. Entende-se que as concepções do profissional estão atreladas também à capacitação em serviço e, se existe pouca ou nenhuma capacitação promovida pela instituição para a qualificação dos profissionais do SAMU no atendimento à pessoa em crise mental, esse atendimento pode se dar de modo inadequado.

No contexto da Reforma Psiquiátrica qualquer esquema que defina crise deve considerar a organização psiquiátrica existente naquela área e naquele momento histórico particu$\operatorname{lar}^{(17)}$. Em relação à organização para o atendimento, o SAMU precisa amparar sua organização de trabalho baseado em Rede de Atenção, já que os resultados apontaram que para atender o sujeito em crise psíquica necessita de um suporte. Atualmente, a Portaria $\mathrm{n}^{\circ} 3088$, de $2011^{(18)}$, é a normativa que institui a Rede de Atenção Psicossocial para pessoas com sofrimento ou transtorno mental e com necessidades decorrentes do uso de crack, álcool e outras drogas, no âmbito do Sistema Único de Saúde (SUS). Assim, no que tange à atenção de urgência e emergência, esta é formada pelos seguintes pontos de atenção: a) SAMU 192; b) Sala de Estabilização; c) UPA 24 horas; d) portas hospitalares de atenção à urgência/ pronto socorro; e) Unidades Básicas de Saúde, entre outros. Portanto, as diretrizes políticas indicam a Rede como caminho da organização do trabalho profissional.

Deste modo, o preparo para atender a crise no Paradigma Psicossocial se pauta em profissionais e gestores comprometidos com o SUS e com a Reforma Psiquiátrica, baseada em rede de atenção. É inerente ao preparo profissional, também, o interesse desse pelo conhecimento e a disposição para atender e discutir os casos dessa especificidade ${ }^{(1)}$. A capacitação deve envolver a discussão da concepção de Crise, que terá uma acolhida como efeito estrutural se for concebida como integrante do modo de o sujeito se posicionar em relação às suas conjunturas conflitivas (subjetivas e sociocultural) que o afligem $^{(6)}$. As situações de crise também podem ser concebidas como: a) grave sintomatologia psiquiátrica aguda; b) grave ruptura das relações familiares e/ou sociais; c) recusa do tratamento psiquiátrico (remédio, internação entre outros), estima 
não necessitar de cuidado, mas aceita contato; d) recusa obstinada de contato com equipes de tratamento psiquiátrico; e) situações de alarme e risco no contexto familiar e/ou social, traduzindo-se em incapacidade de se defrontar com a crise $\mathrm{e}^{(17)}$.

O primeiro contato e os sucessivos momentos de verificação da realidade de vida do sujeito em sofrimento mental compõem o quadro das necessidades: onde vive, onde dorme, o que come, com quanto dinheiro vive, com quem se encontra, quem está à volta, onde trabalha. A escuta favorece uma perspectiva histórica e explicita as contradições e os conflitos que mobilizam a crise ${ }^{(17)}$. Contudo, a existência/sofrimento, o conflito psíquico, a experiência subjetiva radical, a consideração do aparelho psíquico e os fenômenos do inconsciente, a singularidade da condição psicótica e a crise são especificidades da saúde mental que possibilitam o campo da atenção psicossocial ampliar as abordagens psicossociais, através da clínica ampliada, com a finalidade de transformar a vida concreta dos sujeitos ${ }^{(19)}$.

Logo, as capacitações amparadas em metodologias ativas e problematizadoras, com discussão de casos clínicos trazidos da prática profissional vivida, aliadas aos saberes da clínica da atenção psicossocial (psicanálise, esquizoanálise, e materialismo histórico) ${ }^{(8)}$ são caminhos preconizadas pelo paradigma psicossocial para se ter como produto diretrizes organizativas em Rede e clínicas de forma consistente.

A caracterização da crise no modelo de Reforma Psiquiátrica deve levar em conta três dimensões minimamente: a dimensão clínica - o diagnóstico sindrômico e o diagnóstico da estrutura clínica no sentido psicanalítico, a presença de comorbidades; a dimensão do laço social do sujeito - a rede de suporte, família, trabalho, renda, cultura; e, a dimensão da singularidade da pessoa - subjetividade (sujeito do inconsciente) sujeito de direitos e deveres. A posição da pessoa nessas dimensões demarca um processo de crise ${ }^{(20)}$.

No atendimento à pessoa em crise o desafio é entrar na relação a partir da disposição, é como conciliar aproximação e negociação com aceitação e administrar os sentimentos e emoções envolvidos, intervenção esta, cuja habilidade requer no entrelaçamento entre as teorias da subjetividade e da complexa condição humana uma ação criativa. É na produção de um espaço criativo que se tem a possibilidade do dar-se conta do insuportável e do impossível ${ }^{(21)}$.

A crise pensada em um contexto encontra na negociação a possibilidade de se relacionar com a pessoa em crise. $\mathrm{O}$ atendimento é refletido a partir de: como se dá aqui a questão da crise? Quando uma pessoa está em crise ela vai para onde? De que jeito? De que forma? Quem atende? Como atende? Que resposta lhe dá? Como se dá o circuito psiquiátrico em seu território?(22).

Em que pese a representação que o profissional da equipe do SAMU tem sobre a urgência psiquiátrica é algo que provoca inquietude e sentimento como o medo, presente também no DSC1. O que se constata é que a representação da loucura reflete um imaginário social em que este fenômeno incomoda por representar o desconhecido e lidar com incertezas. Este resultado mostra, ainda, uma perspectiva onde a loucura se expressa apenas em sintomas psiquiátricos, ou seja, uma reprodução do senso comum sobre o fenômeno. O que aponta é que a educação, dependendo do modelo teórico-metodológico, tanto pode transformar como emancipar o profissional para atender esta especificidade. Logo, a educação permanente e a supervisão clínica institucional são dispositivos para transformar os dados indicados.

Confrontar o preconceito exige uma ação compromissada para romper barreiras, admitindo espaços de liberdade, valorização do sujeito cidadão e autônomo, ou seja, o desafio que se coloca é buscar novas relações, novas práticas que repensem as ações intervencionistas e limitantes da nossa convivência com a loucura e o louco(23).

O fazer dos trabalhadores do SAMU é pautado na necessidade de segurança e busca o controle do que fazem, porém a estabilidade dos espaços é ilusória e ignorar isso acaba por emperrar os fluxos da vida, causando o sofrimento. Para as equipes do SAMU, quando o assunto é saúde mental, acaba sendo mais parte de um grande problema do que uma solução(1).

No DSC2 está retratada a necessidade de investimentos em capacitação continuada para essa equipe, com foco na prática de intervenção nas situações de crise psíquica. Outro ponto descrito é a organização de um protocolo de atendimento com direcionamento dos passos para a realização deste.

A construção de critérios utilizados na regulação para guiar médicos reguladores de como proceder quando forem acionados para atender à pessoa em crise se revela como uma boa prática nesse campo porque contribui para o funcionamento do SAMU na rede de saúde mental e inclui a pessoa em crise no conjunto dos atendimentos com resolução ${ }^{(1)}$. Para a pessoa em crise ser melhor assistida na realidade sanitária, a constituição de protocolos deve ser norteada pela invenção e criatividade, aliadas ao saber técnico, pois a ciência é uma das formas de explicar o mundo, mas que também é provisória. A quem serve o protocolo? O que significa o protocolo nesse contexto? Seria possível o enquadramento das diferenças singulares das pessoas em protocolos? ${ }^{(1)}$.

A forma de organização do serviço de atendimento pré-hospitalar investigada é pautada na sistematização da assistência, com condutas padronizadas, contendo passos pré-estabelecidos segundo critérios organizados e estudados pela gestão. Com isso, dificultam-se as ações em saúde mental, devido ao fato de o sofrimento psíquico ser composto de intensidade conflitiva.

A busca por uma reorganização da assistência em saúde trouxe uma simplificação do conceito de sistematização e, principalmente, de protocolo, que surgiu como uma estratégia de guia norteador do atendimento, mas passou a ser uma forma sistemática de padronização das ações. Com isso, o sofrimento psíquico composto de conflito subjetivo se fortaleceu pela visão patologizante e de controle dos corpos orientado pela psiquiatria clássica.

É a pessoa em crise psíquica que diz qual é a urgência, assim, cabe aos reguladores uma escuta acolhedora que os farão enxergar que crise está vogando. A partir disso as decisões são tomadas baseadas na ética do suporte à vida, e que seja incentivada a busca do saber do outro a fim de somar o conhecimento das partes e construir o vínculo(1). 
Na afirmação de que "Temos que saber a forma como pegar, a gente tenta não fazer força, mas é preciso", pode-se verificar um entendimento dos profissionais referente às situações de crise psíquica, prioritariamente de contenção, deixando de lado as ações de acolhimento com escuta e diálogo para buscar vínculo e o encaminhamento responsável. A sistematização do trabalho em saúde se caracteriza como uma estratégia metodológica para organização da equipe, mas para nortear a assistência, e não como forma de padronização. A prática assistencial a partir do paradigma psicossocial necessariamente precisa ser individualizada, com foco no sujeito e não na doença.

A leitura pelos serviços de saúde é de que a crise é um diagnóstico com padrões procedimentais estabelecidos, e reforçam-na como um processo de simplificação da própria existência da pessoa à crise, tendo em vista que a pessoa em crise reflete toda uma complexidade da vida. A crise como diagnóstico decorre de medicação e internação, para isso se faz necessário dar outro lugar à mesma na formação profissional ${ }^{(1,17)}$. Então, decorrente disso, é preciso investir em processos educacionais para as equipes de atendimento pré-hospitalar, como um processo teórico-prático, relacionando as ações de atendimento com os princípios do SUS, conforme a afirmação "Acredito que seria necessário um treinamento para a equipe, onde aprenderíamos como agir nas situações".

É fundamental entender a educação como um fenômeno social complexo, através do estabelecimento de relações dialogáveis e horizontalizadas, através do diálogo contínuo, ativo e participativo entre todos os atores ${ }^{(24)}$. Compreender que qualificar o atendimento é problematizá-lo a partir do entendimento de que o conhecimento não está pronto, precisa ser construído. O processo não se faz somente pela transmissão de conteúdos, mas, sim, a partir da construção ativa de todos os atores na construção do conhecimento, procurando meios que o levem ao crescimento e ao aperfeiçoamento de sua capacidade. $\mathrm{O}$ cuidado da crise no campo das urgências requer do profissional a sensibilidade de captar o que se passa na cena, disposição para buscar o que está acontecendo e prestar cuidado a partir da demanda da pessoa, pois na crise o conflito que atravessa a pessoa é algo que coloca o profissional no lugar de interrogado ${ }^{(1)}$.

A educação precisa ser vista como um processo dinâmico e contínuo de construção do conhecimento, pautado no diálogo, em que todos os atores assumam papel ativo no processo de aprendizagem, através de uma abordagem crítica reflexiva da realidade ${ }^{(25)}$, o que reafirma a ideia do Paradigma Psicossocial e que traz à tona um olhar inventivo e complexo, que nem sempre uma teoria tem condições de dar conta. Com isso, faz-se necessário repensar as práticas de saúde, problematizar o entendimento de crise e, principalmente, rever o imaginário social da loucura.

\section{CONCLUSÕES}

Conhecer como os profissionais de atenção pré-hospitalar percebem as intervenções nas pessoas em crise psíquica levou a dois resultados: o primeiro, que as dificuldades no atendimento à pessoa em crise em saúde mental estão atreladas à falta de conhecimento da equipe de como prestar o atendimento; e, o segundo, são as sugestões dos participantes na busca por um atendimento mais próximo do desejado, como a capacitação e a necessidade da sistematização ao atendimento.

Faz-se necessário investir em processo de formação pautado nas novas estratégias de cuidado norteadas pelos princípios do SUS e pelo paradigma psicossocial, valorizando as potencialidades dos profissionais e principalmente as suas criatividades. Com isso, não podemos deixar de salientar a importância da apropriação dos profissionais para a busca de um conhecimento que não pode ser estanque, mas sim, contínuo.

Portanto, este trabalho traz como contribuição científica para o campo da atenção pré-hospitalar, em relação à intervenção em crise psíquica, dados que não são novos, mas que ainda se perpetuam no campo da saúde como: a) reforço do paradigma biomédico nas intervenções; b) baixo investimento da gestão e dos trabalhadores em relação a esta especificidade através da educação e sistematização do cuidado; c) sentimentos e percepções de senso comum frente às emergências psiquiátricas.

\section{REFERÊNCIAS}

1. Jardim KFSB. O serviço ambulatorial móvel de urgência (SAMU) no contexto da reforma psiquiátrica: em análise a experiência de Aracaju/SE [dissertação]. Aracaju (BR): Universidade Federal do Rio Grande do Norte; 2008.

2. Ministério da Saúde (BR), Conselho Nacional de Saúde. Comissão Organizadora da IV Conferência Nacional de Saúde Mental - Intersetorial. Relatório Final da IV Conferência Nacional de Saúde Mental - Intersetorial. Brasília (DF): Ministério da Saúde; 2010.

3. Ministério da Saúde (BR). Portaria 2.048/GM, 05 de novembro de 2002. Aprova o Regulamento Técnico dos Sistemas Estaduais de Urgência e Emergência. Normatiza o serviço de atendimento pré-hospitalar móvel, e estabelece regras que vão desde as especializações da equipe médica até as características dos veículos e os equipamentos a serem utilizados nas ambulâncias. Diário Oficial da União 2002;Seção 1

4. Ministério da Saúde (BR). Portaria 1864/GM de 29 de setembro de 2003. Institui o componente pré-hospitalar móvel da Política Nacional de Atenção às Urgências, por intermédio da implantação de Serviços de Atendimento Móvel de Urgência em municípios e regiões de todo o território brasileiro: SAMU- 192. Diário Oficial da União 2003;Seção 1.

5. Brasil. Lei 10.216, de 06 de abril de 2001. Dispõe sobre a proteção e os direitos das pessoas portadoras de transtornos mentais e redireciona o modelo assistencial em saúde mental. Diário Oficial da União 09 de abr 2001;Seção 1.

6. Costa-Rosa A, Luzio CA, Yasui S. Atenção Psicossocial: 
rumo a um novo paradigma na saúde mental coletiva. In: Amarante $\mathrm{P}$, organizador. Arquivos de Saúde Mental e Atenção Psicossocial. Rio de Janeiro (RJ): Nau; 2003. p. 13-44.

7. Dutra VFD, Rocha RM. O processo de desinstitucionalização psiquiátrica: subsídios para o cuidado integral. Rev Enferm UERJ [Internet]. 2011 [acesso em 06 de junho de 2014];19(3):386-91. Disponível em: http://www.facenf. uerj.br/v19n3/v19n3a08.pdf

8. Costa-Rosa A. O Modo Psicossocial: um paradigma das práticas substitutivas ao modo asilar. In: Amarante PDC, organizador. Ensaios, subjetividades, saúde mental, sociedade. Rio de Janeiro (RJ): Fiocruz; 2000. p. 141-68.

9. Dell'Acqua G, Mezzina R. Resposta à crise: estratégia e intencionalidade da intervenção no serviço psiquiátrico territorial. In: Amarante P, organizador. Arquivos de saúde mental e atenção psicossocial. Rio de Janeiro (RJ): Nau; 2003. p.161-94.

10. Santos JLG. Política de Saúde Pública para usuários de álcool e outras drogas no Brasil: a prática no CAPS AD em Feira de Santana, Bahia, Brasil [dissertação]. Salvador (BA): Universidade Católica do Salvador; 2009.

11. Costa-Rosa A. Atenção Psicossocial além da Reforma Psiquiátrica: contribuição a uma clínica crítica dos processos de subjetivação na Saúde Coletiva. São Paulo (SP): Unesp; 2013.

12. Lefévre F, Lefévrer AMC. O discurso do sujeito coletivo: uma abordagem metodológica em pesquisa qualitativa. Caxias do Sul (RS): EDUCS; 2005.

13. Araújo RR. A Política Pública do Atendimento Pré-Hospitalar na redução da mortalidade por causas externas, no município de Fortaleza (1988 a 2003) [dissertação]. Fortaleza (CE): Universidade Estadual do Ceará; 2005.

14. Gerber AS. Análise dos sistemas de trabalho do serviço de atendimento móvel de urgência - SAMU sob a ótica da sociotécnica [dissertação]. Porto Alegre (RS): Universidade Federal do Rio Grande do Sul; 2010.

15. Conselho Federal de Medicina (BR). Resolução CFM nº. 1451/95. Difine as condições estruturais, materiais e humanas ao atendimento à população nos serviços de Prontos Socorros. Diário Oficial da União 17 mar 1995;Seção 1.
16. Rodrigues J, Pinho LB, Spricigo JS, Santos SMA. Uso da criatividade e da tecnologia no ensino da crise em enfermagem psiquiátrica e saúde mental. SMAD Rev Eletrônica Saúde Mental Alcool Drog. 2010;6 (1):1-15.

17. Jardim K, Dimenstein M. Risco e crise: pensando os pilares da urgência psiquiátrica. Psicol Rev [Internet]. 2007 [acesso em 06 de junho de 2014];13(1):169-90. Disponível em: http://pepsic.bvsalud.org/scielo.php?pid=S1677$-11682007000100011 \&$ script $=$ sci arttext

18. Ministério da Saúde (BR). Portaria nº 3088, de 23 de dezembro de 2011. Institui a Rede de Atenção Psicossocial para pessoas com sofrimento ou transtorno mental e com necessidades decorrentes do uso de crack, álcool e outras drogas, no âmbito do Sistema Único de Saúde. Diário Oficial da União 2011;Seção 1.

19. Vasconcelos EM. Abordagens psicossociais: histórias, teoria e prática no campo. São Paulo (SP): Hucitec; 2008.

20. Campos PJ. O manejo das crises e a rede: o lugar do CAPS III. In: Conselho Federal de Psicologia, organizador. Seminário para avançar a Reforma Psiquiátrica: construindo uma agenda positiva. Brasília (DF): Conselho Federal de Psicologia; 2007. p.97-112.

21. Sterian A. Emergências psiquiátricas: uma abordagem psicanalítica. São Paulo (SP): Casa do Psicólogo; 2001.

22. Nicácio F. O manejo das crises e a rede: o lugar do CAPS III. In: Conselho Federal de Psicologia, organizador. Seminário para Avançar a Reforma Psiquiátrica: construindo uma agenda positiva. Brasília (DF) Conselho Federal de Psicologia; 2007. p.112-129.

23. Mielke FB, Olschowsky A, Pinho LB, Wetzel C, Kantorski LP. Avaliação qualitativa da relação de atores sociais com a loucura em um serviço substitutivo de saúde mental. Rev Bras Enferm. 2012;65(3):501-7.

24. Martins PAF, Alvim NAT. Plano de Cuidados Compartilhado: convergência da proposta educativa problematizadora com a teoria do cuidado cultural de enfermagem. Rev Bras Enferm. 2012;65(2):368-73.

25. Figueiredo MFS, Rodrigues-Neto JF, Leite MTS. Modelos aplicados às atividades de educação em saúde. Rev Bras Enferm. 2010;63(1):117-21. 